\title{
Prediction of risk of adverse events related to percutaneous endoscopic gastrostomy: a retrospective study
}

\author{
Maha Osman Mohamed Shangab*, Niaz Ahmed Shaikh \\ Rashid Hospital, Dubai, UAE
}

\section{Abstract}

\section{Introduction}

Percutaneous endoscopic gastrostomy (PEG) is among the many different approaches used to establish enteral feeding for patients who cannot tolerate oral intake for prolonged periods. First introduced in 1980 by Ponsky and Gauderer [1],

Department of Internal Medicine, Rashid Hospital, Dubai, UAE

Conflict of Interest: None

Correspondence to: Maha Osman Shangab, Internal Medicine Department, Rashid Hospital, Dubai, UAE,

e-mail: moshangab@dha.gov.ae

Conflict of Interest: None

Received 29 May 2019; accepted 6 July 2019; published online 25 July 2019

DOI: https://doi.org/10.20524/aog.2019.0409 the procedure has gradually gained preference over the already established surgical and subsequently developed radiological techniques [2], as several studies have shown its superiority in terms of fewer adverse events as well as reduced mortality rates [3-6].

Despite its feasibility and minimally invasive techniques, this approach is not without risk of adverse events. Several adverse events, either procedure-related or post-procedural, may develop. Post-procedural adverse events can be broadly divided into major and minor [7,8]. Major adverse events are systemic, life-threatening, and can include aspiration pneumonia, massive PEG-related gastrointestinal (GI) hemorrhage, colocutaneous fistula, abdominal wall abscess, and buried bumper syndrome. Minor adverse events include PEG-site infection, peristomal leakage, inadvertent PEG removal, minor GI related bleeding, blocked PEG tube and ileus.

The incidence of adverse events reviewed in the literature varies considerably [9-14]. Some studies have attempted to 
identify markers that would predict the risk of adverse events and early mortality in patients undergoing PEG placement. These were aimed at risk stratifying patients to facilitate proper patient selection and timing for the procedure. Most studies concerning risk prediction for PEG-related adverse events were a reflection of the center's own level of performance. Fewer studies, however, aimed to explore the factors associated with adverse events and prolonged hospitalization for patients with a PEG tube placed in various centers [15].Our study attempts to rectify that deficiency by collecting data from the pool of patients who underwent PEG insertion in our center, as well as in other centers, and were admitted under our service with PEG-related adverse events.

\section{Patients and methods}

\section{Patient selection}

From a 625-bed capacity tertiary center, a total of 311 patients with 661 admissions were recruited into the study. These admissions represented $6.8 \%$ of the total admissions in the included departments. The recruited cases represented all PEG-related adverse events from admissions during a 3-year period, from July 2015 through June 2018. Patients who underwent PEG insertion inside and outside our center were included; as a result, this study does not just reflect our center's own experience.

Data were retrospectively retrieved from electronic medical records. International Classification of Diseases $10^{\text {th }}$ edition (ICD-10) codes for PEG status, as well as all the other PEGrelated adverse events (including aspiration pneumonia), were used to extract records from the medical informatics unit. The codes included the following: K94.1, K94.2, J69.0, Z93.1 and Z43.1.

Cases admitted under services outside general internal medicine, geriatrics, and gastroenterology were excluded for logistical reasons. Aspiration pneumonia not related to PEG feed as well as dependent admissions, i.e., admissions with hospital-acquired infections, were likewise excluded. Finally, a total of 146 patients with 362 admission entries were included in the data analysis. The study design was reviewed and approved by the local ethics committee.

\section{Objectives}

Our aim here was threefold: first to determine the factors associated with the development of PEG-related adverse events and consequent prolonged hospitalization; second, to risk stratify patients and help with timely intervention to minimize the duration of hospitalization and the risk of adverse events; and last, to provide data that reflect a general time and place, i.e., independent adverse events, not just a single center's profile.

\section{Definitions}

Types of PEG-related adverse events were determined and defined based on systemic review articles as well as other studies [7,8]. Adverse events were classified into 2 groups, major and minor, defined as follows. Aspiration pneumonia, hemorrhage, colocutaneous fistula, abdominal wall abscess, and buried bumper syndrome were the major adverse events. Minor adverse events included PEG-site infection, peristomal leakage, inadvertent PEG removal, minor GI-related bleeding, blocked PEG tube, and ileus.

Aspiration pneumonia was defined as the presence of a newly developed symptom (such as a cough, purulent sputum or fever) with an indicative chest X-ray image and a witnessed aspiration. Hemorrhage was defined as bleeding from any side of the PEG tract, presenting with any of the following: external wound bleed, subcutaneous hematoma at PEG site, melena or other forms of GI bleed confirmed to be from PEG site. It qualified as a major complication if the bleeding resulted in hemodynamic instability or a drop in hemoglobin level.

PEG site infection was defined as any erythema with induration around the site of PEG insertion, with or without purulent discharge and without deep abscess collection, together with supportive laboratory evidence of infection. Regarding the PEG site and aspiration pneumonia infections, it is important to note that PEG insertion is usually done in our center after confirming that the patient does not have any active infection, clinically, biochemically and microbiologically. Additionally, during the PEG insertion procedure, a single dose of prophylactic antibiotics, usually a third-generation cephalosporin, is given to all patients. However, the corresponding information from other centers was not available for us to analyze.

Peristomal leakage was limited to any non-purulent oozing of PEG feed material from the PEG insertion site with no sign of infection. PEG tube blockage was identified by the inability to pass feed or flush water down the tube with no visible sign of tube kinking. Ileus included symptomatic cases with suggestive X-ray findings and decreased bowel sounds.

\section{Collection of data}

Patient demographics included age and sex. Potential risk factors were identified by calculating their Charlson comorbidity index, determining the presence of constipation, tracheostomy, and infection at other sites on presentation, as well as recording their serum albumin levels at presentation.

Admission-related data included duration of hospitalization and the service under which they were admitted. Data concerning the PEG-tube included the size of the tube, the duration since PEG placement, and the time since the last PEG-related complication. 


\section{Statistical analysis}

Data were tabulated in a spreadsheet then entered into the Statistical Package for the Social Sciences (SPSS, $20^{\text {th }}$ version) system for analysis. Data were presented as mean and standard deviation (SD) for bell-shaped numerical data; median and interquartile range (IQR) for skewed numerical data; and frequency (\%) for categorical data. Data were analyzed using the chi-square test for categorical data comparisons, Spearman correlations for numerical data, and one-way analysis of variance (ANOVA); the independent-samples KruskalWallis and Mann-Whitney tests were used for comparisons between categorical and numerical data. Variables were tested, when applicable, for the prediction of the 3 following outcomes: 1) length of hospital stay; 2) minor adverse events; and 3) major adverse events. All tests were 2-tailed tests with $\mathrm{P}$-value significant at $<0.05$.

\section{Results}

\section{Demographics and presenting adverse events}

The patients' characteristics and demographics are presented in Table 1. A total of 362 entries were included in the study, of which, 221 (61.0\%) had only minor adverse events, $100(27.6 \%)$ had only major adverse events, and 41 (11.3\%) had both. Eighty (22.1\%) of the adverse events involved PEGsite infection and 128 (35.3\%) were aspiration pneumonia, as presented in Table 2. Of the patients presenting with PEGrelated adverse events, 85 (23.5\%) were tracheostomized compared with $39(30.5 \%)$ in patients presenting with aspiration pneumonia.

Almost 90\% of cases had PEG tube insertion secondary to neurological dysfunction. Neurological dysfunction included neurological causes that resulted in swallowing difficulty and weakness of deglutition muscles. Examples included poststroke, Parkinsonism, multiple sclerosis, etc. Among the 34 patients who underwent initial PEG tube insertion because of malnutrition, the PEG was replaced by percutaneous endoscopic jejunostomy in 5 cases because of recurrent admissions with aspiration pneumonia, and in one case after a barium study demonstrated delayed gastric emptying and a high percentage of regurgitation.

Half of the cases $(n=11)$ presented with minor GI-related bleeding were on single antiplatelet therapy. This compares to $71.4 \%(n=6)$ of cases presenting with major GI-related bleeding. All cases presenting with GI-related bleeding were managed conservatively: proton pump inhibitor infusion and blood transfusion for massive bleeding, and wound care and PEG tube care for minor bleeding.

The mortality rate was $2.5 \%(n=9)$. These cases were secondary to septic shock and multi-organ failure.
Table 1 Basic characteristics of the study population

\begin{tabular}{|c|c|}
\hline Characteristics & Value \\
\hline Age (years) & [79], 13 \\
\hline Female sex & $196(54.1 \%)$ \\
\hline Length of hospital stay & [3], 9 \\
\hline \multicolumn{2}{|l|}{ Admitting service } \\
\hline Internal medicine & $206(56.9 \%)$ \\
\hline Emergency service only & $106(29.3 \%)$ \\
\hline Gastroenterology & $27(7.5 \%)$ \\
\hline Geriatrics & $23(6.4 \%)$ \\
\hline \multicolumn{2}{|l|}{ Indications for PEG tube placement } \\
\hline Neurological dysfunction & $324(89.5 \%)$ \\
\hline Nutritional & $34(9.4 \%)$ \\
\hline Head and neck tumor & $2(0.6 \%)$ \\
\hline Other & $1(0.3 \%)$ \\
\hline Charlson comorbidity index & [7], 3 \\
\hline Presence of tracheostomy & $85(23.5 \%)$ \\
\hline Presence of constipation & $66(18.2 \%)$ \\
\hline \multicolumn{2}{|l|}{ Other site infection at presentation } \\
\hline None & $292(80.7 \%)$ \\
\hline Urinary & $46(12.7 \%)$ \\
\hline Bed sores & $18(5 \%)$ \\
\hline Chest & $6(1.7 \%)$ \\
\hline Serum albumin at presentation & $\begin{array}{l}3.40 \pm 0.51 \\
\mathrm{mg} / \mathrm{dL}\end{array}$ \\
\hline \multicolumn{2}{|l|}{ PEG tube-related characteristics } \\
\hline Time since last PEG replacement (in months) & [5], 8 \\
\hline $\begin{array}{l}\text { Time since last PEG related complication (in } \\
\text { months) }\end{array}$ & {$[4], 7$} \\
\hline PEG size (in Fr) & {$[24], 4$} \\
\hline \multicolumn{2}{|l|}{ Number of presenting adverse events } \\
\hline Minor adverse events alone & $221(61.0 \%)$ \\
\hline Major adverse events alone & $100(27.6 \%)$ \\
\hline Both minor and major adverse events & $41(11.3 \%)$ \\
\hline
\end{tabular}

$\mathrm{N}(\%)$ [median], interquartile range (mean) \pm standard deviation PEG, percutaneous endoscopic gastrostomy

\section{Inferential statistics}

Tests for length of hospital stay as an outcome, as presented in Table 3, showed that the level of serum albumin at presentation had a strong negative correlation $(\mathrm{P}<0.001)$ and Charlson comorbidity index a strong positive correlation $(\mathrm{P}<0.001)$. Female patients had a significantly longer duration of hospitalization $(\mathrm{P}=0.012)$.

Presenting with a major PEG-related adverse event resulted in a prolonged duration of hospitalization $(\mathrm{P}<0.001)$. Urinary or bedsore infection at presentation also resulted in a longer average duration of hospital stay $(\mathrm{P}<0.001)$. Finally, the 
Table 2 Admission complication and related length of hospitalization

\begin{tabular}{lcc} 
Complications & $\begin{array}{c}\text { Rate of } \\
\text { presentation } \\
\mathrm{n}(\%)\end{array}$ & $\begin{array}{c}\text { Length of } \\
\text { hospitalization }\end{array}$ \\
\hline Minor adverse events & $101(27.9)$ & {$[10], 15$} \\
No minor complication & $80(22.1)$ & {$[8], 11$} \\
PEG site infection & $66(18.2)$ & {$[1], 0$} \\
Inadvertent PEG removal & $46(12.7)$ & {$[1], 1$} \\
Peristomal leakage & $26(7.2)$ & {$[1], 3$} \\
PEG tube blockage & $22(6.1)$ & {$[2], 3$} \\
Minor GI-related bleeding & $21(5.8)$ & {$[2], 4$} \\
Ileus & & \\
Major adverse events & $221(61)$ & {$[1], 3$} \\
No major complication & $128(35.4)$ & {$[9], 14$} \\
Aspiration pneumonia & $7(1.9)$ & {$[12], 48$} \\
Massive GI-related bleeding & $2(0.6)$ & $(115.5), 146$ \\
Colocutaneous fistula & $2(0.6)$ & $(111), 97.58$ \\
Abdominal wall abscess & $2(0.6)$ & $(151), 210.71$ \\
Buried bumper syndrome & & \\
\hline
\end{tabular}

${ }^{*}\left[\right.$ median], interquartile range ${ }^{*}$ (mean), standard deviation

PEG, percutaneous endoscopic gastrostomy; GI, gastrointestinal

Table 3 Tests for length of hospital stay predictors

\begin{tabular}{lcc}
\hline & $\begin{array}{c}\text { Correlation } \\
\text { coefficient }\end{array}$ & $\begin{array}{c}\text { P-value } \\
\text { (sig.) }\end{array}$ \\
\hline Spearman's rho & 0.045 & 0.394 \\
Age & 0.191 & $<0.001$ \\
Charlson comorbidity index & -0.273 & $<0.001$ \\
Albumin level at presentation & 0.045 & 0.416 \\
Time since PEG placement & -0.006 & 0.914 \\
Time since last PEG related & & \\
complication & & \\
Mann-Witney test / Kruskall-Wallis & & 0.002 \\
Sex & & 0.971 \\
Presence of constipation & & 0.022 \\
Presence of tracheostomy & & $<0.001$ \\
Presence of infection at other sites & & $<0.001$ \\
\hline Presenting complication & & \\
\hline PEG, percutaneous endoscopic gastrostomy & &
\end{tabular}

presence of tracheostomy resulted in a lengthier duration of hospitalization $(\mathrm{P}=0.022)$.

Albumin levels varied significantly among patients presenting with either a major or minor complication $(\mathrm{P}<0.001$ and $\mathrm{P}=0.026$ ). Higher Charlson comorbidity index scores were seen in cases with aspiration pneumonia as compared to cases presenting with minor adverse event $(\mathrm{P}=0.004)$. Lower scores were observed in cases of inadvertent PEG removal or PEGsite infection compared to cases with only a major adverse
Table 4 Tests for major and minor adverse events predictors

\begin{tabular}{lccc} 
Kruskall-Wallis & $\begin{array}{c}\text { Major adverse } \\
\text { events }\end{array}$ & & $\begin{array}{c}\text { Minor adverse } \\
\text { events }\end{array}$ \\
\cline { 2 - 2 } & P-value (sig.) & & P-value (sig.) \\
\hline Age & 0.184 & & 0.342 \\
Charlson comorbidity index & 0.004 & & $<0.001$ \\
\hline $\begin{array}{l}\text { Albumin level* } \\
\text { Time since PEG } \\
\text { replacement }\end{array}$ & $<0.001$ & & 0.026 \\
$\begin{array}{l}\text { Time since PEG-related } \\
\text { complication }\end{array}$ & 0.230 & & 0.069 \\
PEG size & 0.517 & 0.054 \\
\hline
\end{tabular}

${ }^{*}$ Albumin association tested with one-way analysis of variance (ANOVA) $P E G$, percutaneous endoscopic gastrostomy

event $(\mathrm{P}<0.001)$. Minor adverse events, on the other hand, were affected by PEG size $(\mathrm{P}<0.001)$, where $\mathrm{PEG}$-tube blockage and inadvertent $\mathrm{PEG}$ removal were more common among patients with a smaller PEG size, as shown in Table 4.

Table 5 shows the frequency of the presenting adverse events and their other characteristics in relation to sex, the presence of constipation, and infection at other sites at presentation. Adverse events were classified as very early (less than a month), early (1-6 months) or late ( $>6$ months) in relation to the time since PEG placement for further analysis; there was no significant difference among either minor or major adverse events ( $\mathrm{P}=0.526, \mathrm{P}=0.277$ respectively).

\section{Discussion}

PEG is the standard method of establishing prolonged enteral feeding for patients unable to sustain oral intake [3-6]. Despite its feasibility, simple techniques for placement and the added benefit of improved nutrition, it has been associated with a risk of adverse events $[7,8]$. The number of admissions due to PEG-related adverse events in our center was 125 of a total of 3227 admissions (3.87\%) per year in the general internal medicine, gastroenterology and geriatric departments. This apparently high percentage can be explained by the fact that our center is the major tertiary center in the city, while many of these patients underwent PEG insertion at other centers and came to us as referrals from other secondary and primary centers.

The incidence of adverse events reviewed in the literature differs significantly. Blomberg et al found a one-month postoperative incidence of adverse events of 39\%, dropping to $28 \%$ a month later [9]. Gang and Kim reported a higher incidence of short-term adverse events in pediatrics, reaching 84.6\% [10]. Ermis et al followed-up patients for a year after PEG insertion and demonstrated an $18 \%$ rate of adverse events [11]. Lockett, in an earlier study showed a comparable $16 \%$ rate of adverse events [12]. Other studies have recorded complication 
Table 5 Admission adverse events and other characteristics

\begin{tabular}{|c|c|c|c|c|c|c|c|c|c|}
\hline \multirow[t]{2}{*}{ Complication } & \multicolumn{2}{|c|}{ Sex } & \multicolumn{2}{|c|}{ Presence of constipation } & \multicolumn{4}{|c|}{ Other site infection } & \multirow[t]{2}{*}{ Total } \\
\hline & Female & Male & Yes & No & None & Urine & Chest & Bed sore & \\
\hline \multicolumn{10}{|c|}{ Minor complication } \\
\hline $\begin{array}{l}\text { No minor } \\
\text { complication }\end{array}$ & $41(40.6 \%)$ & $60(59.4 \%)$ & $17(16.8 \%)$ & $84(83.2 \%)$ & $77(76.2 \%)$ & $16(15.8 \%)$ & & $8(7.9 \%)$ & 101 \\
\hline $\begin{array}{l}\text { PEG site } \\
\text { infection }\end{array}$ & $45(56.3 \%)$ & $35(43.8 \%)$ & $14(17.5 \%)$ & $66(82.5 \%)$ & $51(63.8 \%)$ & $19(23.8 \%)$ & $3(3.8 \%)$ & $7(8.8 \%)$ & 80 \\
\hline $\begin{array}{l}\text { Peristomal } \\
\text { leakage }\end{array}$ & $32(69.6 \%)$ & $14(30.4 \%)$ & $2(4.3 \%)$ & $44(95.7 \%)$ & $42(91.3 \%)$ & $2(4.3 \%)$ & $2(4.3 \%)$ & & 46 \\
\hline Ileus & $12(57.1 \%)$ & $9(42.9 \%)$ & $18(85.7 \%)$ & $3(14.3 \%)$ & $18(85.7 \%)$ & $2(9.5 \%)$ & & $1(4.8 \%)$ & 21 \\
\hline $\begin{array}{l}\text { Inadvertent } \\
\text { PEG } \\
\text { removal }\end{array}$ & $41(62.1 \%)$ & $25(37.9 \%)$ & $7(10.6 \%)$ & $59(89.4 \%)$ & $63(95.5 \%)$ & $2(3 \%)$ & & $1(1.5 \%)$ & 66 \\
\hline $\begin{array}{l}\text { PEG tube } \\
\text { blockage }\end{array}$ & $14(53.8 \%)$ & $12(46.2 \%)$ & $4(15.4 \%)$ & $22(84.6 \%)$ & $22(84.6 \%)$ & $3(11.5 \%)$ & $1(3.8 \%)$ & & 26 \\
\hline $\begin{array}{l}\text { Minor GI- } \\
\text { related } \\
\text { bleeding }\end{array}$ & $11(50 \%)$ & $11(50 \%)$ & $4(18.2 \%)$ & $18(81.8 \%)$ & $19(86.4 \%)$ & $2(9.1 \%)$ & & $1(4.5 \%)$ & 22 \\
\hline Total & $196(54.1 \%)$ & $166(45.9 \%)$ & $66(18.2 \%)$ & $296(81.8 \%)$ & $292(80.7 \%)$ & $46(12.7 \%)$ & $6(1.7 \%)$ & $18(5 \%)$ & 362 \\
\hline
\end{tabular}

Major adverse events

\begin{tabular}{|c|c|c|c|c|c|c|c|c|c|}
\hline $\begin{array}{l}\text { No major } \\
\text { complication }\end{array}$ & $138(62.4 \%)$ & $83(37.6 \%)$ & $43(19.5 \%)$ & $178(80.5 \%)$ & $194(87.8 \%)$ & $18(8.2 \%)$ & $4(1.8 \%)$ & $5(2.3 \%)$ & 221 \\
\hline $\begin{array}{l}\text { Aspiration } \\
\text { pneumonia }\end{array}$ & $48(37.5 \%)$ & $80(62.5 \%)$ & $23(18 \%)$ & $105(82 \%)$ & 89 (69.5\%) & $26(20.3 \%)$ & & $13(10.2 \%)$ & 128 \\
\hline $\begin{array}{l}\text { Massive GI- } \\
\text { related } \\
\text { bleeding }\end{array}$ & $4(57.1 \%)$ & $3(42.9 \%)$ & & 7 & $5(71.4 \%)$ & $2(28.6 \%)$ & & & 7 \\
\hline $\begin{array}{l}\text { Colocutaneous } \\
\text { fistula }\end{array}$ & 2 & & & 2 & & & 2 & & 2 \\
\hline $\begin{array}{l}\text { Abdominal } \\
\text { wall } \\
\text { abscess }\end{array}$ & 2 & & & 2 & 2 & & & & 2 \\
\hline $\begin{array}{l}\text { Buried } \\
\text { bumper } \\
\text { syndrome }\end{array}$ & 2 & & & 2 & 2 & & & & 2 \\
\hline Total & $196(54.1 \%)$ & $83(45.9 \%)$ & $66(18.2 \%)$ & $296(81.8 \%)$ & $292(80.7 \%)$ & $46(12.7 \%)$ & $6(1.7 \%)$ & $18(5 \%)$ & 362 \\
\hline
\end{tabular}

rates ranging between $19-31 \%[13,14]$. This variation in the reported adverse events can be explained by the small sample sizes and the short follow-up durations in these studies. On the other hand, the mortality rate in these studies ranged between $33 \%$ and $3.3 \%[3,9,13]$.

We conducted the present study after analyzing data presented in earlier studies associating the risks of adverse events and mortality with certain variables related to the patient's general clinical status, as well as our clinical observations of other potential factors. Among the findings of this study, neurologic diseases were the most common indications for PEG placement; this was consistent with other previous studies [16-18].
PEG site infection rated as the most common presenting complication, constituting $21 \%(n=71)$ of all admissions. This did not differ from previous studies confirming its high prevalence, especially in the acute postprocedural period [19-20]. All cases that underwent PEG insertion in our center received prophylactic antibiotics, as per hospital protocol, in the form of a single dose of ceftriaxone $2 \mathrm{~g}$ intravenously on the day of PEG insertion.

Of the patients admitted with PEG-site infection, 36.2\% $(n=29)$ had an infection in other sites, with urinary tract infections being the most common (Table 5). We were unable, however, to draw any conclusions from this regarding tests of significance, as the numbers were insufficient. A previously conducted study revealed that urinary tract infection, together 
with old age ( $>75$ years) and previous aspiration pneumonia were factors associated with a higher early mortality/30-day mortality rate [21]. No study, however, associated its presence with a higher chance of developing PEG site infection.

Of the 21 patients presenting with ileus, $85.7 \%(n=18)$ had a background of chronic constipation. From this, it is possible to infer that having a PEG tube placement does not necessarily increase the risk of presenting with ileus in the long run, unless the patient has underlying chronic constipation due to another reason.

Among the major adverse events, buried bumper syndrome was found in 2 cases only $(0.6 \%)$. This did not vary from the previously reported incidence of $0.3-2.4 \%$ [22-24].

One of the main findings in the study was the significant association between the level of albumin at presentation and the presenting complication $(\mathrm{P}=0.026$ for minor adverse events and $\mathrm{P}<0.001$ for major adverse events), as well as a strong negative correlation between the albumin serum level and the length of hospitalization (correlation coefficient $-0.273, \mathrm{P}<0.001$ ). Several previous studies have observed that low serum albumin level was a predictor of early mortality and later discharge after PEG insertion [16-17,25-29]. These results give rise to the idea of utilizing albumin as a risk predictor, not only for the likelihood of developing a PEG-related complication, but also for predicting the length of hospitalization. These findings also suggest that nutritional management during PEG feeding should be monitored carefully. Previous studies showed a relation to this suggestion in the finding that early post-PEG mortality can be reduced if patients are pre-assessed by a multidisciplinary nutrition team [30].

The Charlson comorbidity index is a scoring system used to predict 10-year survival in patients with multiple comorbidities. It takes 15 diseases into account and assigns a different score to each of them. It was first suggested by Charlson et al in a study demonstrating an increased risk of death with the increasing cumulative score [31]. The subjects in the study had a median index score of 7 , giving an estimated 10 -year survival rate of $0 \%$, as was validated in other studies [32]. The index score here was found to be a predictor of major adverse events, being higher among patients admitted with aspiration pneumonia $(\mathrm{P}=0.004)$, as well as lower among patients with either $\mathrm{PEG}$ site infection or inadvertent PEG removal compared with having only a major complication $(\mathrm{P}<0.001)$. Previous studies involving the Charlson index only showed its utility at predicting longterm morbidity (after 30 days from PEG insertion) but not at predicting adverse events [13]. In our study, the Charlson index was also found to be a good predictor of the length of hospitalization (correlation coefficient 0.191, $\mathrm{P}<0.001$ ).

According to a Mexican study, these significant associations of comorbidities and albumin level were observed more in the older population, as they independently predicted longterm mortality [33]. C-reactive protein level on presentation has also been studied as a predictor of early mortality [13-15], as has severe hypernatremia, especially in the immediate preprocedural period [34]; however, because of insufficient data, our study did not include these variables for testing.

A KASID study (Korean Association for the Study of Intestinal Diseases) showed a strong correlation between PEG tube diameters and the development of adverse events, with an odds ratio of 1.26 for 1-Fr increments [18]. Our study showed a consistent result by demonstrating a significant association between the PEG tube diameter and minor adverse events $(\mathrm{P}<0.001)$, where PEG-tube blockage and inadvertent PEG removal were more common among patients with a smaller PEG size.

Our study differed from previous studies in that we documented the clinical profile of patients presenting with PEG-related adverse events who had undergone PEG placement at different time intervals and did not reflect the center's rate of adverse events, as several patients had had their PEG placed in other specialized centers. Our aim with this change of approach was to reflect the general time-independent adverse events, which constitute most of the cases seen in practice. Adverse events can occur at any time after PEG placement, and having factors generally associated with these adverse events would help predict the long-term management of such cases. It would also help provide more careful observation and diligent care for patients at higher risk of developing complications, in order to prevent their occurrence and to intervene in a timely manner.

The study was limited, however, by several factors. First, there was no control arm for comparison, i.e., patients with uncomplicated PEG tube feeding, making it impossible to estimate the odds ratio of developing these adverse events with certain potential risk factors. Second, the retrospective design of the study resulted in some missing data from medical records, as well as a potential for incorrect assessment of adverse events and possible error in the rate of adverse events. Third, this study was a single center study and thus may not reflect general population characteristics.

In conclusion, PEG placement remains a safe and effective means of providing enteral feeding and improvement in general nutritional status. The patient's general medical condition, as

\section{Summary Box}

\section{What is already known:}

- Percutaneous endoscopic gastrostomy (PEG)related adverse events are a common reason for admission in patients with a PEG tube

\section{What the new findings are:}

- Low albumin levels are associated with the development of PEG-related adverse events as well as prolonged hospitalization

- A higher Charlson comorbidity index predicts prolonged hospitalization and an increased risk of aspiration pneumonia

- Having urinary or bed sore infection at presentation results in a longer hospital stay

- PEG tube blockage and inadvertent PEG removal are more prevalent with smaller PEG tube sizes 
scored by the Charlson comorbidity index, and nutritional status, measured by serum albumin level, are 2 significant risk predictors for developing adverse events related to their PEG feeding. Having a sound understanding of these risk predictors would help improve inpatient and outpatient care of high-risk individuals to reduce their risk of developing adverse events and need for prolonged hospitalization, while optimizing their baseline status and lifestyle.

\section{References}

1. Gauderer MW, Ponsky JL, Izant RJ Jr. Gastrostomy without laparotomy: a percutaneous endoscopic technique. 1980. Nutrition 1998;14:736-738.

2. de Baere T, Chapot R, Kuoch V, et al. Percutaneous gastrostomy with fluoroscopic guidance: single-center experience in 500 consecutive cancer patients. Radiology 1999;210:651-654.

3. Galaski A, Peng WW, Ellis M, Darling P, Common A, Tucker E. Gastrostomy tube placement by radiological versus endoscopic methods in an acute care setting: a retrospective review of frequency, indications, complications and outcomes. Can J Gastroenterol 2009;23:109-114.

4. Silas AM, Pearce LF, Lestina LS, et al. Percutaneous radiologic gastrostomy versus percutaneous endoscopic gastrostomy: a comparison of indications, complications and outcomes in 370 patients. Eur J Radiol 2005;56:84-90.

5. Bankhead RR, Fisher CA, Rolandelli RH. Gastrostomy tube placement outcomes: comparison of surgical, endoscopic, and laparoscopic methods. Nutr Clin Pract 2005;20:607-612.

6. Rustom IK, Jebreel A, Tayyab M, England RJ, Stafford ND. Percutaneous endoscopic, radiological and surgical gastrostomy tubes: a comparison study in head and neck cancer patients. J Laryngol Otol 2006;120:463-466.

7. Schrag SP, Sharma R, Jaik NP, et al. Complications related to percutaneous endoscopic gastrostomy (PEG) tubes. A comprehensive clinical review. J Gastrointestin Liver Dis 2007;16:407-418.

8. Rahnemai-Azar AA, Rahnemaiazar AA, Naghshizadian R, Kurtz A, Farkas DT. Percutaneous endoscopic gastrostomy: indications, technique, complications and management. World $J$ Gastroenterol 2014;20:7739-7751.

9. Blomberg J, Lagergren J, Martin L, Mattsson F, Lagergren P. Complications after percutaneous endoscopic gastrostomy in a prospective study. Scand J Gastroenterol 2012;47:737-742.

10. Gang MH, Kim JY. Short-term complications of percutaneous endoscopic gastrostomy according to the type of technique. Pediatr Gastroenterol Hepatol Nutr 2014;17:214-222.

11. Ermis F, Ozel M, Oncu K, et al. Indications, complications and longterm follow-up of patients undergoing percutaneous endoscopic gastrostomy: a retrospective study. Wien Klin Wochenschr 2012;124:148-153.

12. Lockett MA, Templeton ML, Byrne TK, Norcross ED. Percutaneous endoscopic gastrostomy complications in a tertiary-care center. Am Surg 2002;68:117-120.

13. Figueiredo FA, da Costa MC, Pelosi AD, Martins RN, Machado L, Francioni E. Predicting outcomes and complications of percutaneous endoscopic gastrostomy. Endoscopy 2007;39:333-338.

14. Gundogan K, Yurci A, Coskun R, et al. Outcomes of percutaneous endoscopic gastrostomy in hospitalized patients at a tertiary care center in Turkey. Eur J Clin Nutr 2014;68:437-440.

15. Anderloni A, Di Leo M, Barzaghi F, et al. Complications and early mortality in percutaneous endoscopic gastrostomy placement in Lombardy: A multicenter prospective cohort study. Dig Liver Dis 2019 [Epub ahead of print]. doi: 10.1016/j.dld.2019.03.024
16. Lee C, Im JP, Kim JW, et al; Small Intestine Research Group of the Korean Association for the Study of Intestinal Disease (KASID). Risk factors for complications and mortality of percutaneous endoscopic gastrostomy: a multicenter, retrospective study. Surg Endosc 2013;27:3806-3815.

17. Pih GY, Na HK, Ahn JY, et al. Risk factors for complications and mortality of percutaneous endoscopic gastrostomy insertion. BMC Gastroenterol 2018;18:101.

18. Park SK, Kim JY, Koh SJ, Lee YJ, Jang HJ, Park SJ; Small Intestine and Nutrition Research Group of the Korean Association for the Study of Intestinal Diseases (KASID). Complications of percutaneous endoscopic and radiologic gastrostomy tube insertion: a KASID (Korean Association for the Study of Intestinal Diseases) study. Surg Endosc 2019;33:750-756.

19. Vizhi K, Rao HB, Venu RP. Percutaneous endoscopic gastrostomy site infections-Incidence and risk factors. Indian J Gastroenterol 2018;37:103-107.

20. Muñoz-Dávila MJ, Xandri Ruipera JM, Yagüe Guirao G, Salvador García C, Segovia Hernández M. [Gastrostomy tubes: indications and infectious complications in a tertiary hospital]. Rev Esp Quimioter 2017;30:334-340.

21. Light VL, Slezak FA, Porter JA, Gerson LW, McCord G. Predictive factors for early mortality after percutaneous endoscopic gastrostomy. Gastrointest Endosc 1995;42:330-335.

22. Tsai JJ, Lin HJ. Clinical manifestations and management of buried bumper syndrome in patients with percutaneous endoscopic gastrostomy. Gastrointest Endosc 2009;69:1193.

23. Baskin WN. Acute complications associated with bedside placement of feeding tubes. Nutr Clin Pract 2006;21:40-55.

24. Yuruker S, Koca B, Karabicak I, Kuru B, Ozen N. Percutaneous endoscopic gastrostomy: technical problems, adverse events, and management. Indian J Surg 2015;77:1159-1164.

25. Gumaste VV, Bhamidimarri KR, Bansal R, Sidhu L, Baum J, Walfish A. Factors predicting early discharge and mortality in post-percutaneous endoscopic gastrostomy patients. Ann Gastroenterol 2014;27:42-47.

26. Blomberg J, Lagergren P, Martin L, Mattsson F, Lagergren J. Albumin and C-reactive protein levels predict short-term mortality after percutaneous endoscopic gastrostomy in a prospective cohort study. Gastrointest Endosc 2011;73:29-36.

27. Tominaga N, Shimoda R, Iwakiri R, et al. Low serum albumin level is risk factor for patients with percutaneous endoscopic gastrostomy. Intern Med 2010;49:2283-2288.

28. Yokohama S, Aoshima M. [Risk factors of early mortality after percutaneous endoscopic gastrostomy: a retrospective study]. Nihon Shokakibyo Gakkai Zasshi 2009;106:1313-1320.

29. Karasahin O, Tasar PT, Timur O, et al. High C-reactive protein and low albumin levels predict high 30 -day mortality in patients undergoing percutaneous endoscopic gastrotomy. Gastroenterology Res 2017;10:172-176.

30. Tanswell I, Barrett D, Emm C, et al. Assessment by a multidisciplinary clinical nutrition team before percutaneous endoscopic gastrostomy placement reduces early postprocedure mortality. JPEN J Parenter Enteral Nutr 2007;31:205-211.

31. Charlson ME, Pompei P, Ales KL, MacKenzie CR. A new method of classifying prognostic comorbidity in longitudinal studies: development and validation. J Chronic Dis 1987;40:373-383.

32. Quan H, Li B, Couris CM, et al. Updating and validating the Charlson comorbidity index and score for risk adjustment in hospital discharge abstracts using data from 6 countries. Am J Epidemiol 2011;173:676-682.

33. Cortés-Flores AO, Álvarez-Villaseñor AS, Fuentes-Orozco C, et al. Long-term outcome after percutaneous endoscopic gastrostomy in geriatric Mexican patients. Geriatr Gerontol Int 2015;15:19-26.

34. Muratori R, Lisotti A, Fusaroli P, et al. Severe hypernatremia as a predictor of mortality after percutaneous endoscopic gastrostomy (PEG) placement. Dig Liver Dis 2017;49:181-187. 